\title{
Developmental and evolutionary assumptions in a study about the impact of premature birth and low income on mother-infant interaction
}

\author{
Marina Fuertes • Anabela Faria • Hélia Soares • \\ Patricia Crittenden
}

Received: 19 May 2008 /Revised: 8 October 2008 / Accepted: 17 November 2008 /Published online: 3 December 2008

(C) Springer-Verlag and ISPA 2008

\begin{abstract}
In order to study the impact of premature birth and low income on mother-infant interaction, four Portuguese samples were gathered: full-term, middle-class $(n=99)$; premature, middle-class $(n=63)$; full-term, low income $(n=22)$; and premature, low income $(n=21)$. Infants were filmed in a free play situation with their mothers, and the results were scored using the CARE Index. By means of multinomial regression analysis, social economic status (SES) was found to be the best predictor of maternal sensitivity and infant cooperative behavior within a set of medical and social factors. Contrary to the expectations of the cumulative risk perspective, two factors of risk (premature birth together with low SES) were as negative for mother-infant interaction as low SES solely. In this study, as previous studies have shown, maternal sensitivity
\end{abstract}

Communicated by R.F. Oliveira

M. Fuertes $(\bowtie)$

Child Development Unit, Children's Hospital,

1295 Boylston Street, Suite 320,

Boston, MA 02215, USA

e-mail: marina.fuertes@childrens.harvard.edu

A. Faria

Hospital Espírito de Santo de Angra do Heroísmo,

Azores, Portugal

H. Soares

Escola Superior de Enfermagem de Angra do Heroísmo,

Azores, Portugal

P. Crittenden

Family Institute of Miami,

Miami, FL, USA and infant cooperative behavior were highly correlated, as was maternal control with infant compliance. Our results further indicate that, when maternal lack of responsiveness is high, the infant displays passive behavior, whereas when the maternal lack of responsiveness is medium, the infant displays difficult behavior. Indeed, our findings suggest that, in these cases, the link between types of maternal and infant interactive behavior is more dependent on the degree of maternal lack of responsiveness than it is on birth status or SES. The results will be discussed under a developmental and evolutionary reasoning.

Keywords Mother-infant interaction · Risks · Evolutionary approach

\section{Introduction}

The present research has two main goals: (1) to explore the effect of premature birth and low income both isolated and aggregated on maternal sensitivity and infant cooperative behavior; and (2) to investigate the link between maternal types of behavior (sensitive, controlling, or unresponsive) and infant styles of interactive behavior (cooperative, compliant, difficult, and passive) under the influence of low social economic status (SES) and premature birth.

Previous studies have linked maternal sensitivity and infant cooperative behavior with secure attachment and better socio-emotional outcomes (Feldman 2007; Kobak et al. 2006). So, we wonder how premature birth and low SES affect the dyadic interchange. Indeed, both variables, often linked, are associated with adverse developmental outcomes for infants. Yet, little research has been conducted to 
investigate the effect of each factor per se and the dynamics involved by the interaction of both factors.

Risks related with premature birth and low SES

Prematurity affects infants' development directly and affects parents indirectly through their infants' behavior and their worry regarding its health and viability (Allen et al. 2004). Specifically, preterm infants have been described as being less alert, attentive, active, and responsive than infants born at full term (Crnic et al. 1983; Goldberg and DiVitto 1995; Tronick et al. 1985), and their mothers tend to be more intrusive, controlling, or psychologically withdrawn (Barnard and Kelly 1990; Forcada-Guex et al. 2006; Goldberg and DiVitto 1995; Muller-Nix et al. 2004). Nevertheless, some studies show that premature infants become socially and emotionally competent by 6 months of corrected age (Gerner 1999; Schermann-Eizirik et al. 1997).

Low SES, on the other hand, has a more persistent negative effect. Income affects parents directly, making more difficult day-to-day management of basic lifesupporting tasks such as obtaining food, shelter, and medical care. When these needs are unmet, infants suffer doubly both, through the insufficiency of these basics and also through the relative unavailability of their parents, who are preoccupied with meeting these needs. Longitudinal studies have shown that there is a negative effect of low SES on infants' social, emotional, and cognitive development (Furstenberg et al. 1999; Sameroff et al. 1987a). The negative impact of low SES can be partially explained by the number of associated risk factors and by the interaction of these factors. Indeed, Sameroff et al. (1987a) found that SES is highly linked with a set of environmental risk factors among which are maternal education, family support, stressful life events, maternal anxiety, parental representations, beliefs, and attitudes.

Little research has been conducted to evaluate the direct impact of SES variation on mother-infant relationships. Nevertheless, in low SES samples, the incidence of insecure attachment is higher than the incidence of insecure attachment usually observed in normative samples from middle classes (Kobak et al. 2006). It has been suggested by Muller-Nix et al. (2004) that, because low SES raises parents' level of stress, it may negatively influence motherchild interaction. Finally, there is some empirical evidence that infants from poor families are more likely to be exposed to marital violence compared with those from middle-class background (Grych et al. 2000). Thus, we expected that low SES would have a higher negative impact on maternal sensitivity and infant cooperative behavior than premature birth and that family economic status would affect their habits, attitudes, and behaviors more signifi- cantly than premature birth. Thus, for example, the breastfeeding duration in mothers of prematurely born infants, which is not influenced by degree of prematurity, size at birth, or neonatal disorders, is certainly affected by SES (Flacking et al. 2007a, b)

Association between premature birth and low SES on mother-infant interaction

Premature birth and low SES are often linked; indeed, the highest rates of premature birth were found among poor families (NCHS 2008). Furthermore, the association between low SES and prematurity has been found across generations (Emanuel et al. 2004). In addition, several studies have shown that SES plays an important role in modulating the effect of perinatal factors (Belsky et al. 2007; Werner et al. 1968). Moreover, prematurity is consistently related to later physical and psychological development only when combined with persistently poor environmental circumstances.

A body of research indicates that the aggregate impact of several risks cannot be described merely as the sum of such adversities (for review, see Sameroff and Fiese 2000). Indeed, many child-developmental theorists argue that the cumulative risk is the "high risk" condition for development (Rutter 2006; Sameroff and Fiese 2000). Attachment literature provides a good example of the adverse association of other risk factors with premature birth. In relatively healthy infants from educated middle-class samples, premature birth is not typically associated with a higher rate of attachment insecurity (Easterbrooks 1989; Frodi and Thompson 1985). However, when samples are characterized by additional risk factors such as low socioeconomic status (Wille 1991), low maternal education (Pederson and Moran 1996), comorbid infant health problems (Plunkett et al. 1986), or maternal depression (Hagen 2002; Poehlmann and Fiese 2001), the association of risk factors affects development in more negative and complex ways than each isolated risk condition. According to this reasoning, we expect that middle SES dyads with full-term babies would have the highest rate of maternal sensitivity and infant cooperation compared with the other three conditions and that dyads with one risk factor would have higher sensitivity and cooperation scores than dyads with two risk factors (i.e., low SES dyads with a premature baby).

Styles of maternal and infant interaction under the influence of premature birth and low SES

An extensive literature, performed mainly with normal samples, indicates that maternal sensitivity is associated 
with positive infant responses, whereas maternal control and intrusive and punitive behavior are linked with infant submission and compliance (for a review, see Belsky et al. 1995). If parents provide attentive, warm, and careful care, infants tend to use their parents as a secure base; that is, they look for parent's protection when under threat and explore when conditions are safe (Bowlby 1969). In normal interactions, these children tend to be reciprocal and cooperative, express their feelings openly, and use social and play experiences as opportunities to learn and develop (Ainsworth et al. 1978; Crittenden 1995; Goldberg and DiVitto 1995).On the other hand, more threatened children would work harder to elicit parental care, becoming more demanding when fussiness elicited attention and more compulsively inhibited when the attention was itself threatening (Crittenden and DiLalla 1988; Isabella 1993). For example, in studies of abuse and neglect, it has been shown that infants improve their probability of survival by becoming less difficult and more compliant with abusive mothers and more engaging and less passive with neglectful mothers (Hrdy 1999). In cases of very severe neglect, however, when mothers withdraw, infants become passive, and neither mother nor infant thrives (Crittenden 1992, 1995).

Such relations between parent and infant types of interactive behavior are, of course, probabilistic. Although maternal sensitivity contributes significantly towards attachment security, this variable alone only has a modest impact on attachment status (De Wolff and van IJzendoorn 1997). Our aim here is to study how such associations between maternal types of behavior (sensitive, controlling, or unresponsive) and infant styles of interactive behavior (cooperative, compliant, difficult, and passive) are affected by SES and premature birth.

Current study This research is unique in testing the relative risk potential of low income and premature birth on maternal sensitivity and infant cooperative behavior by studying four independent samples that combine all possible risk/nonrisk conditions: full term, middle class; premature, middle class; full term, low income; and premature, low income. Furthermore, potential independent predictors (birth status, SES, infant health status, gestational weight, gestational age, infant gender, maternal years of education, maternal age, and marital status) of maternal and infant interactive behavior were tested in stepwise regression, and a final model was selected. According to previous literature, we expect that low SES be the key factor shaping maternal sensitivity and infant cooperative behavior. Moreover, the association between premature birth and low SES should have a higher negative impact on mother-infant interaction when compared with each isolated factor. Last, we investigate the possible correlations between the maternal (sensitivity, control/intrusiveness, and unresponsivity) and infant (cooperative, compliant, difficult, passive) interactive types of behavior in each sample.

\section{Materials and methods}

\section{Subjects}

The subjects were: (1) 99 mother-infant dyads in which the infants were full term from middle SES homes, (2) 22 dyads with full-term infants born from low SES homes, (3) 63 dyads with infants born before 36 weeks of gestational age from the middle SES homes, and (4) 21 dyads with infants born before 36 weeks of gestational age from low SES homes. No infants with handicap or illness or mothers with mental health or drug/alcohol addiction problems were included in the study. The two low SES samples had annual incomes ranging between $2,100 €$ and $7,000 €$ per year; thus, only very poor families were included in the low SES group.

The subjects from the full-term middle-class group and all preterm mother-infant dyads were recruited from Portuguese hospitals. Information from hospital medical records concerning birth weight, gestational age, and perinatal conditions was used to assign infants to the preterm samples. The sample of infants born at term to lowincome parents was identified with the help of early intervention teams. In this sample, information concerning infant perinatal conditions and health status was colleted from the infant's medical record. Both low-income samples had some support from Portuguese Social Services and/or early intervention teams.

Because 3-month-old infants are able to self regulate in the context of social interaction with their mothers and to contribute to social exchange regulation (Cohn and Tronick 1987; Tronick et al. 1982), we selected infants older than 3 months. Table 1 summarizes the infant and maternal information for the four groups.

Infants born prematurely had significantly lower gestational weight and age than full-term infants (according to the Mann-Whitney test, $p<0.001$ ). There were no significant differences between the full-term middle-class and low-income samples and between the two samples of preterms regarding these factors.

Procedure

The study aims and procedures were designed in accordance with the instructions of the Portuguese Ethics 
Table 1 Infant and maternal demographics
Full term, middle

class $(N=99)$

Premature, middle class $(N=63)$

Full term, low income

Premature, $(N=22)$

$(N=21)$

\begin{tabular}{|c|c|c|c|c|}
\hline \multicolumn{5}{|l|}{ Sex } \\
\hline $\mathrm{F}$ & 49 & 28 & 9 & 9 \\
\hline M & 50 & 35 & 13 & 12 \\
\hline \multicolumn{5}{|l|}{ Age corrected (months) } \\
\hline$M$ & 5.9 & 8.0 & 8.4 & 7.7 \\
\hline SD & 2.17 & 3.23 & 3.31 & 3.02 \\
\hline (Minimum-maximum) & $(3-15)$ & $(3-12)$ & $(3-15)$ & $(3-12)$ \\
\hline \multicolumn{5}{|l|}{ Gestational age (weeks) } \\
\hline$M$ & 38.96 & 33,81 & 38.45 & 32.76 \\
\hline $\mathrm{SD}$ & 1.35 & 1.84 & 0.77 & 2.47 \\
\hline (Minimum-maximum) & $(37-42)$ & $(29-36)$ & $(36-41)$ & $(26-36)$ \\
\hline \multicolumn{5}{|l|}{ Gestational weight (g) } \\
\hline M & 3,228 & 2,095 & 2,913 & $1,925.19$ \\
\hline $\mathrm{SD}$ & 0.435 & 0.470 & 0.472 & 0.557 \\
\hline (Minimum-maximum) & $(1850-4580)$ & $\left(\begin{array}{lll}1 & 050-2 & 285\end{array}\right)$ & $(2$ 165-3 870) & $(915-2700)$ \\
\hline Infants with health problems & $26.3 \%$ & $49.2 \%$ & $45.5 \%$ & $71.4 \%$ \\
\hline \multicolumn{5}{|l|}{ Mother's years of education (\%) } \\
\hline Primary School (0-6 years) & 14.1 & 27.0 & 54.5 & 57.1 \\
\hline High School (7-12 years) & 49.5 & 36.5 & 27.3 & 42.9 \\
\hline Degree from 3 to 5 years college & 36.4 & 36.5 & 18.2 & 0 \\
\hline \multicolumn{5}{|l|}{ Mother's age $(\%)$} \\
\hline $17-22$ years & 13.1 & 1.6 & 0 & 47.6 \\
\hline $23-28$ years & 36.4 & 22.2 & 31.8 & 23.8 \\
\hline 29-34 years & 27.3 & 39.7 & 40.9 & 23.8 \\
\hline Over 35 years & 23.2 & 36.5 & 27.3 & 4.8 \\
\hline
\end{tabular}

Commission for People Rights Protection. Potential families were contacted personally. During the contact, the researchers explained the purpose and method of the investigation and requested the family's participation in the study. The data collection started, after eligible mothers gave their informed consent, with a brief interview with the mothers to collect demographic data such as maternal education and medical assistance during pregnancy.

Following the CARE Index Manual instructions (Crittenden 2003), each dyad was videotaped for about $3 \mathrm{~min}$ in an unstructured play situation. The mothers were asked to play with their infants as they usually would. A blanket was spread on the floor with a large variety of toys placed in easy reach. All the rooms were brightly lit, and the ambient sounds were reduced, for example, by turning off radios, televisions, and asking for silence.

\section{Measure}

Maternal sensitivity and infant cooperative behavior The CARE Index was used to assess the quality of infant and adult interaction. The CARE Index consists of 52 items organized around seven aspects of dyadic behavior; facial expression, verbal expression, position and body contact, affection, turn-taking contingencies, control, and choice of activity. Each adult and, separately, each infant were evaluated on these seven aspects of interactive behavior. For each aspect, there are three items describing the quality of adult behavior and four describing infant behavior. For adults, one item describes sensitive behavior, one controlling behavior, and one unresponsive behavior. Four items describe the quality of the infant's interactive behaviorcooperative, compliant, difficult, and passive. Although the adult is scored separately from the infant, mother and infant are each scored from the other's perspective; for example, if the mother smiles when the infant is distressed, it is considered nonsensitive behavior from the infant's perspective. In sum, the coder should select the option in each category which best describes adult or infant behavior in the context of the other's behavior.

The CARE Index procedure is particularly suited to samples with variability in age, in our case, from birth to 24 months.

Three coders scored each case independently and, in order to obtain consensus, the group of coders discussed all dissimilarities. The consensus scores were used as the data. 
The overall inter-coder agreement for major classification prior to conferencing was above $80 \%$. All coders were blind to studied hypotheses and group status of the dyadsSES and prematurity. One of the coders obtained reliability with the author of CARE Index, and the two other coders were trained by the first coder.

Some studies reported the CARE index validity as a tool to assess mother-infant quality of interaction and provided different outcomes using the measure for middle class, lowrisk mothers, deaf mothers, low-income mothers, mothers with mental retardation, abusive mothers, and neglectful mothers (Dilalla and Crittenden 1990).

\section{Results}

Plan of the analysis

Three sets of statistical analyses were carried out to test the hypotheses presented in this study. First, nonparametric statistics were performed to test the differences in maternal sensitivity and infant cooperative behavior among the four samples. By comparing each pair of samples, we expected to identify which samples had higher and lower levels of maternal sensitivity and infant cooperative behavior. Although nonparametric tests are less powerful than parametric counterparts, the difference in size among our samples and the differences in variance on the studied variables justify the choice of nonparametric tests. In the second set of analysis, a separate stepwise regression analysis was performed to identify the predictors of maternal sensitivity and infant cooperative behavior. Each regression analysis contained the following independent factors: birth status (full-term or preterm), SES, infant health status, gestational weight, gestational age, infant gender, maternal years of education, and maternal age. The last set of analysis explored the correlation between maternal and infant types of interactive behavior among samples. For all sets of analyses, alpha was set at 0.05 .
Differences in maternal sensitivity and infant cooperative behavior according to sample in bivariate analyses

Levene's test for equality of variance indicates that the parametric tests cannot be used because the maternal sensitivity and infant cooperation variances differ significantly among the samples. Thus, a Mann-Whitney test was performed to compare each two groups.

Table 2 shows the descriptive analyses for maternal sensitivity and infant cooperative behavior in each sample. The mean of maternal sensitivity and infant cooperation varied among samples (Table 3). Comparing each two groups, maternal sensitivity was higher in the full-term, middle-class sample than in the three risk groups. Moreover, maternal sensitivity was higher in infants born prematurely from middle-class homes than in infants born in low-income homes. No significant difference was found between the two low-income samples, both preterm and full term.

Predictors of maternal and infant interactive behavior in multivariate analyses

In order to determine the impact of a set of independent variables - birth status (full term or preterm), SES, infant health status, gestational weight, gestational age, infant gender, maternal years of education, maternal age, and marital status on maternal sensitivity and infant cooperative behavior - a stepwise regression analyses was performed. The order of the independent variables taken into the equation was determined using statistical measures without any manipulation.

Table 4 indicates that three variables, SES, infant health status, and maternal years of education, predict both sensitivity and cooperative behavior. In fact, both stepwise regression analyses for maternal sensitivity and for infant cooperative behavior excluded the same variables, namely, birth status, gestational weight, gestational age, infant gender, and maternal age.
Table 2 Descriptive analyses of maternal sensitivity and infant cooperative behavior scores

\begin{tabular}{lllll}
\hline Scales & Samples & $M$ & SD & Minimum-maximum \\
\hline Maternal sensitivity & Full term, middle class & 7.42 & 2.19 & $2-13$ \\
& Premature, middle class & 6.63 & 2.60 & $2-12$ \\
& Full term, low income & 5.14 & 1.55 & $3-8$ \\
Infant cooperative behavior & Premature, low income & 5.00 & 1.84 & $2-9$ \\
& Full term, middle class & 7.38 & 2.16 & $3-14$ \\
& Premature, middle class & 6.65 & 2.57 & $2-12$ \\
& Full term, low income & 4.91 & 1.31 & $3-8$ \\
& Premature, low income & 5.24 & 2.05 & $2-9$ \\
\hline
\end{tabular}


Table 3 Mann-Whitney $U$ test for differences in maternal sensitivity and infant cooperative behavior among samples

\begin{tabular}{|c|c|c|c|c|c|}
\hline Scales & Samples & $\begin{array}{l}\text { Full term, } \\
\text { middle class }\end{array}$ & $\begin{array}{l}\text { Premature, } \\
\text { middle class }\end{array}$ & $\begin{array}{l}\text { Full term, } \\
\text { low income }\end{array}$ & $\begin{array}{l}\text { Premature, } \\
\text { low income }\end{array}$ \\
\hline \multirow[t]{3}{*}{ Maternal sensitivity } & Full term, middle class & \multirow[t]{3}{*}{-} & $2495^{*}$ & $424 * * *$ & $407 * * *$ \\
\hline & Premature, middle class & & - & $465^{*}$ & $418^{* *}$ \\
\hline & Full term, low income & & & - & 215 \\
\hline \multirow[t]{3}{*}{ Infant cooperative behavior } & Full term, middle class & \multirow[t]{3}{*}{-} & $2533^{*}$ & $349 * * *$ & $484 * * *$ \\
\hline & Premature, middle class & & - & $411 * * *$ & $439 *$ \\
\hline & Full term, low income & & & - & 225 \\
\hline
\end{tabular}

${ }^{*} p<0.05 ; * * p<0.005 ; * * * p<0.001$

In terms of maternal sensitivity, the SES variable is the first predictor provided by the stepwise analysis. This variable alone explains $12.4 \%$ of the total observed variance. The contribution of SES into the variance is meaningful, and $R^{2}$ is significant $(F(1,201)=28.345 ; p<$ 0.001). In the second step of the regression, SES together with maternal education explained $17.6 \%$ of the variance. Thus, the 0.052 of $R^{2}$ increase is significant $(F(2,200)=$ $21.300 ; p<0.001)$. When infant health status joins SES and $R^{2}$ maternal education on the third step of the regression, the explained variance increased $4.1 \%$ (total $21.7 \%$ ). Thus, in this last model, the increase 0.041 of $R^{2}$ is meaningful $(F(3,199)=18.385 ; p<0.001)$.

For infant cooperative behavior, SES was the first predictor provided in the stepwise analysis. This factor explains $12.5 \%$ of the total observed variance, and the $R^{2}$ is meaningful $(F(1,201)=28.613$.; $p<0.001)$. The second model generated by the stepwise regression included infant health status. Through this variable, the variance explained increased to $16.7 \%$, and $R^{2}$ significantly increased 0.042 $(F(2,200)=19.989 ; p<0.001)$. In the third analysis step, when maternal years of education is added to the previous model (with SES and infant health status), the explained variance increased $19.6 \%$, and $R^{2}$ significantly increase $0.029(F(3,199)=16.181 ; p<0.001)$.
Correlations between maternal and infant types of interactive behavior

In all groups, maternal sensitivity was positively correlated with infant cooperation (Table 5). The dyadic behavioral pattern of "mother sensitive - infant cooperative" occurred in all four groups, but it was more frequent among dyads with full-term infants from middle-class homes. Similarly, "maternal controlling behavior and infant compliance" were correlated in all four samples.

Among the four samples, different correlations were found concerning maternal unresponsive behavior. Infant difficultness was positively correlated with maternal unresponsiveness in the full-term, middle-class sample but not in the other three groups. In the other groups, maternal unresponsiveness was correlated with infant passivity.

\section{Discussion}

The present research gathers four independent samples combining two risk vs. nonrisk conditions: preterm vs. full term and low vs. middle SES to study the impact of birth and income status on maternal and infant's interactive behavior. Moreover, the association between maternal types

Table 4 Stepwise regression analysis results for maternal sensitivity and infant cooperative

\begin{tabular}{llrrr}
\hline Dependent variables & Independent variables & $B$ & $B$ standard error & $B$ \\
\hline Maternal sensitivity & SES & 1.363 & 0.397 & 0.233 \\
& Infant health status & -1.016 & 0.313 & -0.208 \\
& Maternal years of education & 0.696 & 0.201 & $0.176^{* *}$ \\
Infant cooperative behavior & SES & 1.463 & 0.398 & 0.232 \\
& Infant health status & -0.970 & 0.314 & 0.252 \\
& Maternal years of education & 0.544 & 0.201 & -0.200 \\
& & & $0.127^{* *}$ \\
& & & $0.167^{* *}$ \\
\hline
\end{tabular}

${ }^{*} p<0 .{ }^{*} p<0.05 ; * * p<0.005 ; * * * p<0.001$ 
Table 5 Correlation (Spearman's rho coefficient) between child and adult behavioral scales according to each sample

\begin{tabular}{|c|c|c|c|c|}
\hline \multirow[t]{2}{*}{ Samples } & \multirow[t]{2}{*}{ Child scales } & \multicolumn{3}{|l|}{ Adult scales } \\
\hline & & Sensitive & Controlling & Unresponsive \\
\hline \multirow{4}{*}{$\begin{array}{l}\text { Full-term, } \\
\text { middle class }\end{array}$} & Cooperative & $0.885^{* *}$ & $-0.477 * *$ & $-0.293 * *$ \\
\hline & Compliant & $-0.334 * *$ & $0.348 * *$ & -0.098 \\
\hline & Difficult & -0.124 & -0.027 & $0.223^{*}$ \\
\hline & Passive & -0.098 & -0.016 & 0.096 \\
\hline \multirow{4}{*}{$\begin{array}{l}\text { Premature, } \\
\text { middle class }\end{array}$} & Cooperative & $0.967 * * *$ & $-0.419^{* *}$ & $-0.295^{*}$ \\
\hline & Compliant & $-0.447 * *$ & $0.634 * *$ & $-0.313^{*}$ \\
\hline & Difficult & -0.124 & -0.012 & 0.234 \\
\hline & Passive & 0.111 & $-0.635^{* *}$ & $0.476^{* *}$ \\
\hline \multirow{4}{*}{$\begin{array}{l}\text { Full term, low } \\
\text { income }\end{array}$} & Cooperative & $0.972 * * *$ & $-0.452 * *$ & $-0.393 * *$ \\
\hline & Compliant & $-0.461 * *$ & $0.687 * *$ & $-0.280^{*}$ \\
\hline & Difficult & -0.217 & -0.009 & 0.178 \\
\hline & Passive & 0.056 & $-0.534^{* *}$ & $0.575^{* *}$ \\
\hline \multirow{4}{*}{$\begin{array}{l}\text { Premature, low } \\
\text { income }\end{array}$} & Cooperative & $0.888 * * *$ & -0.171 & -0.193 \\
\hline & Compliant & -0.232 & $0.731 * *$ & $-0.586^{* *}$ \\
\hline & Difficult & -0.070 & -0.002 & 0.073 \\
\hline & Passive & 0.026 & $-0.703 * *$ & $0.624 * *$ \\
\hline
\end{tabular}

${ }^{*} p<0.05 ; * * p<0.005 ; * * * p<0.001$

of behavior (sensitive, controlling, or unresponsive) and infant styles of interactive behavior (cooperative, compliant, difficult, and passive) under the influence of low SES and premature birth was investigated.

\section{Differences in maternal sensitivity and infant cooperative} behavior according to sample Results from nonparametric bivariate analyses indicate that the least sensitive mothers and the least cooperative babies were from low SES samples regardless of the infant birth status-full or preterm. Compared with other groups, middle SES mothers with full-term infants were the most sensitive and their infant the most cooperative. Finally, middle SES dyads with babies prematurely born were more sensitive and cooperative, respectively, than low SES dyads with babies prematurely born. Therefore, these findings do not entirely corroborate the cumulative risk perspective. According to this developmental approach, the adverse condition for mother-infant interaction is the addition of risk factors (Rutter 2006; Sameroff and Fiese 2000). Supporting this perspective, the mothers from the sample without risk conditions (mothers of full-term infants from middle-class families) displayed more attentive, affectionate, and responsive behavior than mothers from risk samples. Analogous results were found for infant cooperative behavior. Moreover, our results indicate that maternal sensitivity and infant cooperation are more likely to decrease in the sample with infants prematurely born from families with low income than from middle class (i.e., one risk condition had better performance against two risk conditions). However, this study does not indicate that two risk factors are more adverse for maternal sensitivity than one single risk condition. Indeed, no significant differences were found between low-income samples-preterm and full-term. Therefore, contrary to this hypothesis, the economic factor by itself seems to affect mother-infant interaction as much as two risk conditions aggregated, in this case, premature birth and low income. Furthermore, when we take in consideration demographic data, it is clear that other factors such as maternal education, maternal age (early motherhood) and infant health are potentially more adverse in prematurely born infants from a low SES background than in full term from a low SES background. Although the cumulative risk perspective has been highly empirically supported in the past, perhaps in some cases (or with some variables), there is a point where things cannot get worse or, possibly, some clusters of risk are more dangerous than others.

Predictors of maternal and infant types of interactive behavior The independent contributions of several factorsbirth status, SES, infant health status, gestational weight, gestational age, infant gender, maternal years of education, maternal age, and marital status - to maternal sensitivity and infant cooperative behavior were evaluated using a stepwise multinomial regression analyses. Three factors were retained as significant predictors for maternal and infant behavior: SES, infant health status, and maternal education.

Again, the analyses reveal that SES has a powerful impact on mother-infant quality of interaction. According to the transactional perspective, child development is seen as a product of continuous dynamic interactions of the child and the experience provided by his or her family and social context (Sameroff and Fiese 2000). From this perspective, the number of risk factors (e.g., infant health and regulatory problems, parental unemployment, conjugal problems, lower social support) likely to be associated with low SES may directly affect the infant's emotional expression and parent's responses in a reciprocal and transactional process and may affect indirectly the relationship by affecting the resources available, the time and duration of interactions, and by stressing other involved persons. Indeed, SES has multiple influences on mother-infant relationship. Hence, it is probable that families' income be the most significant factor on shaping maternal and infant interactive behavior.

The developmental transactional explanation about human interactions can be enriching with an evolutionary reasoning. In social species like humankind, individual reproductive fitness may be strongly associated with "social fitness" (Tooby and Cosmides 1992). Social success affects individual mating opportunities, stability of relationships, access to resources, and general life conditions (Geary 
2005). In many species, health signals and immunity performance are crucial when one chooses a mate, while in human species, social and economical status are further important attributes to seek in a future partner (Bjorklund and Blasi 2005; Bjorklund et al. 2002; Salmon 2005).

Difficulty in providing food during the pre- and postnatal phase, care support (e.g., health, hygiene, warmth), protection, and assistance in establishing a hierarchical social position contribute to raise the cost of parental investment in low SES families (Salmon 2005). This cost is balanced with children probable social outcome (social competitiveness and ability to acquire resources required in adulthood). Childrens' later social success requires several strengths such as refine social competence and good educational outcomes. However, children from low SES homes tend to have worst academic and developmental results than children from upper classes (Furstenberg et al. 1999; Noble et al. 2005, 2006, 2007; Sameroff et al. 1987b). Furthermore, children from low SES engage more in aggressive and antisocial behaviors (Hay et al. 2006; Nobile et al. 2007; Noble et al. 2005, 2007; Veenstra et al. 2005). Thus, not only is the cost of raising a child high, but for lowresource parents, the expectable social outcome is not commiserated with the effort.

A second important factor of our study that must be acknowledged is infant health status. This affects infant's self-regulatory behaviors and, by consequence, affects infant contribution for mother-infant quality of interaction (and indirectly parental behavior). From an evolutionary approach, infant health status may affect directly parental behavior. Trivers's parental investment theory predicts that parents will invest more in offspring who are expected to survive than those who are not (Trivers 1972). Despite using a small sample of only seven mothers and their twin infants, Mann (1992) demonstrated that, at 8 months, the healthier twin, rather than the twin who was more fun or who first left the hospital, received more positive maternal responses. Moreover, infants with physical disabilities or chronic diseases are at high risk of maltreatment and infanticide (Daly and Wilson 1988; Sullivan and Knutson 1998, 2000; Zirpoli 1986; Zirpoli and Bell 1987). That is especially true when parents are young and have more opportunities to birth future babies (Tifferet et al. 2007). Our findings suggest that health status has a greater effect than premature birth on maternal sensitivity. According to the evolutionary approach, the explanation is related with infant's likelihood of survival though reproductive age. Maybe health status is more directly related it than premature birth.

The final factor retained by the stepwise regression is maternal education. SES is a composite measure of economic and educational status, and these factors (income and years of education) are highly correlated in most studies within Western countries. For this reason, the effect of these factors when dissociated remains unclear. Fuertes et al. $(2006,2008)$ have shown, in samples where economics is not correlated with education, that maternal education affects mother's representation of their infant's difficult temperament, maternal sensitivity, and motherinfant attachment. In the present work, maternal education and SES are highly correlated and, for that reason, it is difficult to support further speculations about maternal education contribution per se on mother-infant quality of interaction. Hence, more detailed investigation with this variable aggregated and dissociated from family income is necessary on mother-infant studies.

In summary, from a development point of view, low SES may affect directly both parents' and infant's behavior negatively. On the other hand, infant health status only affects dyadic interaction indirectly by decreasing infants' expression of positive affect and social attend (Tronick et al. 1985). Thus, infants contribute to a reciprocal process of mutual negative inter-influences. From an evolutionary point of view, both low SES and infant health status affect parent's reproductive fitness. Low SES may affect infant sexual reproductive success, and health status might affect infant viability. We speculate that threats on parents caused by low SES conditions may also affect the parent's survival, diminishing their future chances of reproduction.

Correlations between maternal and infant types of interactive behavior In agreement with previous studies (Crittenden 1981, 1992; Dilalla and Crittenden 1990), we found a correlation in all samples between maternal sensitivity and infant cooperation and maternal control with infant compliance. Moreover, our results suggest that the relation with maternal lack of responsiveness differs by subsample. That is, maternal unresponsiveness correlates with infant difficultness only in the full-term, middle-class sample. Infants from the other three groups at risk react to maternal lack of responsiveness with passivity. However, it should be noted that lack of maternal responsiveness is significantly lower in the full-term, middle-class sample than the other samples. Therefore, as expected, the moderate levels of maternal unresponsive behavior can increase infant difficultness, while high levels of maternal unresponsive behavior promote infant passivity. We speculate that the degree of maternal unresponsivity may affect infant's response. If the social interchange was only a moderate problem (e.g., the adult is not very involved or offers unappealing play), then infants can struggle to increase or shape the mother's response. However, in face of almost no interaction, infants do not have a chance to learn how to take part in social interaction.

Hence, our results suggest that there are specific styles of mother-infant interaction and that these patterns of inter- 
action vary according to both dyadic and environmental conditions. According to the dynamic maturational model (DMM) approach, an attachment meta-theory that combines developmental, evolutionary, and systemic frameworks, these mother-infant styles of interaction (maternal sensitivity/infant cooperation; maternal control/infant compliance; maternal moderate unresponsivity/infant difficultness, and maternal high unresponsivity/infant passivity) are formed partly on the basis of the infant's ability to organize coping strategies to adapt to parental style of behavior (Crittenden 1999; Simpson 1999). These infant styles of behavior are preconscious and self-protective; furthermore, they affect the way that infants enact their role in interaction and interpret future experiences. Indeed, these types of infant behavior are short-term adaptations to maternal behavior. Maternal behavior, on the other hand, depends on individual, social, and cultural factors, as well as the infant's reproductive fitness. That is, mothers' behavior is more tied to long-term adaptation.

In conclusion, our results suggest that, in order to understand the cumulative impact of risk factors on mother-infant interaction, one should considerer both the effect of risk factors addition and the relative strength of each risk condition. Contrary to remote developmental perspectives (reproductive risk approaches), here a social risk (low SES) had a greater impact on maternal and infant behavior than a medical condition: premature birth or health status (Sameroff 1975). From an evolutionary point of view, such results can be explained attending that low SES affects infant prospective social success (and probably parental and infantile survival), and because health status affects infant's viability, both factors (family low SES and infant health status) jeopardize parents' and infants' reproductive inclusive fitness. In consequence, parental investment and quality of care providing is dependent on family low SES and infant health status. Finally, our findings also give support to DMM reasoning that children' strategies for eliciting parental care are directly related to parental strategy for providing that care (Crittenden 1995, 1999). Independently from the risk status, the infant interactive strategies were highly coherent with maternal responses (Crittenden 1999).

The major limitation of our study concerns the differences regarding the samples size. The relatively small size of low SES samples prevented us from evaluating potential indirect effects of medical and social variables on maternal and infant behavior and to use more refined parametric analyses. Additional longitudinal research with larger samples is needed to investigate how multiple factors from different levels of analysis - and the complex interplay among them-may contribute to mother-infant quality of interaction. Despite this limitation, our study is unique in combining all possible risk/nonrisk conditions (full term, middle class; premature, middle class; full term, low income; and premature, low income) to study the particular effect of SES and birth status on mother-infant relationship, providing new and more accurate information on this topic.

Acknowledgments The study was made possible with a postdoctoral fellowship from Fundação para a Ciência e Tecnologia (SFRH/BPD/ 26726/2006). The authors gratefully acknowledge the comments of Edward Tronick, Ana Kirby, and David Hibberd. The authors declare that the experiments comply with the current laws of the country in which they were performed.

\section{References}

Ainsworth MD, Blehar M, Waters E, Wall S (1978) Patterns of attachment: a psychological study of the strange situation. Lawrence Erlbaum Associates, New Jersey

Allen EC, Manuel JC, Legault C, Naughton MJ, Pivor C, O'Shea TM (2004) Perception of child vulnerability among mothers of former premature infants. Pediatrics 113(2):267-273

Barnard KE, Kelly JF (1990) Assessment of parent-child interaction. In: Meisels SJ, Shonkoff JP (eds) Handbook of early childhood intervention. Cambridge University, New York, pp 278-302

Belsky J, Rosenberger K, Crnic K (1995) The origins of attachment security: classical and contextual determinants. In: Goldberg S, Muir R, Kerr J (eds) Attachment theory: social, developmental and clinical perspectives. Analytic Press, Hillsdale, NJ, pp 153-183

Belsky J, Bakermans-Kranenburg MJ, van Ijzendoorn MH (2007) For better and for worse: Differential susceptibility to environmental influences. Curr Dir Psychol Sci 16(6):300-304

Bjorklund DF, Blasi CH (2005) Evolutionary developmental psychology. In: Buss DM (ed) The handbook of evolutionary psychology. Wiley, Hoboken, NJ, pp 828-850

Bjorklund DF, Yunger JL, Pellegrini AD (2002) The evolution of parenting and evolutionary approaches to childrearing. In: Bornstein MH (ed) Handbook of parenting, vol. III: biology of parenting. Lawrence Erlbaum Associates, Mahwah, NJ, pp 3-30

Bowlby J (1969) Attachment and loss, vol. I. Penguim Books, London

Cohn JF, Tronick EZ (1987) Mother infant face-to-face interactionthe sequence of dyadic states at 3,6, and 9 months. Dev Psychol 23(1):68-77

Crittenden PM (1981) Relationships at risk. In: Belsky J, Nezworski T (eds) Clinical implications of attachment. Lawrence Erlbaum Association, Hillsdale, NJ, pp 136-174

Crittenden PM (1992) Children's strategies for coping with adverse home environments: an interpretation using attachment theory. Child Abuse Neglect 16:329-343

Crittenden PM (1995) Attachment and psychopathology. In: Goldberg S, Muir R, Kerr J (eds) Attachment theory: social, developmental, and clinical perspectives. The Analytic Press, Hillsdale, NJ, pp 367-406

Crittenden PM (1999) Atypical attachment in infancy and early childhood among children at developmental risk. (VII: Danger and development: the organization of self-protective strategies). Monogr Soc Res Child Dev 64(3):145-171

Crittenden PM (2003) CARE-Index manual. Family Relations Institute, Miami

Crittenden PM, DiLalla DL (1988) Compulsive compliance: the development of an inhibitory coping strategy in infancy. J Abnorm Child Psychol 16(5):585-599

Crnic KA, Ragozin SA, Greenberg MT, Robinson MN, Basham RB (1983) Social interaction and development competence of preterm and full-term during the first year of life. Child Dev 54 (5):1199-1210 
Daly M, Wilson M (1988) Homicide. Aldine de Gruyter, New York

De Wolff MS, van IJzendoorn MH (1997) Sensitivity and attachment: a meta-analysis on parental antecedents of infant attachment. Child Dev 68(4):571-591

Dilalla DL, Crittenden PM (1990) Dimensions of maltreated children's home behavior: a factor analytic approach. Infant Behav Dev 13:439-460

Easterbrooks MA (1989) Quality of attachment to mother and to father - effects of perinatal risk status. Child Dev 60(4):825-830

Emanuel I, Kimpo C, Moceri V (2004) The association of maternal growth and socio-economic measures with infant birthweight in four ethnic groups. Int J Epidemiol 33(6):1236-1242

Feldman R (2007) Parent-infant synchrony: biological foundations and developmental outcomes. Curr Dir Psychol Sci 16(6):340-345

Flacking R, Nyqvist KH, Ewald U (2007a) Effects of socioeconomic status on breastfeeding duration in mothers of preterm and term infants. Eur J Public Health 17(6):579-584

Flacking R, Wallin L, Ewald U (2007b) Perinatal and socioeconomic determinants of breastfeeding duration in very preterm infants. Acta Paediatr 96(8):1126-1130

Forcada-Guex M, Pierrehumbert B, Borghini A, Moessinger A, Muller-Nix C (2006) Early dyadic patterns of mother-infant interactions and outcomes of prematurity at 18 months. Pediatrics 118(1):E107-E114

Frodi A, Thompson R (1985) Infants' affective responses in the strange situation: effects of prematurity and of quality of attachment. Child Dev 56(5):1280-1290

Fuertes M, Lopes dos Santos P, Beeghly M, Tronick E (2006) More than maternal sensitivity shapes attachment: infant coping and temperament. Ann NY Acad Sci 1094:292-296

Fuertes M, Lopes dos Santos P, Beeghly M, Tronick E (2008) Infant coping and maternal interactive behaviour predict attachment in a Portuguese sample of healthy preterm infants. Eur Psychol (in press)

Furstenberg FJ, Cook T, Eccles J, Elder GH, Sameroff AJ (1999) Urban families and adolescent success. University Chicago Press, Chicago

Geary D (2005) Evolution of paternal investment. In: Buss D (ed) The handbook of evolutionary psychology. Willey, NJ, pp 483-505

Gerner EM (1999) Emotional interaction in a group of preterm infants at 3 and 6 months of corrected age. Child Dev 8(3):117-128

Goldberg S, DiVitto B (1995) Parenting children born preterm. In: Bronstein M (ed) Handbook of parenting, vol. I. Erlbaum, Hillsdale, NJ, pp 209-231

Grych JH, Fincham FD, Jouriles EN, McDonald R (2000) Interparental conflict and child adjustment: testing the mediational role of appraisals in the cognitive-contextual framework. Child Dev 71(6):1648-1661

Hagen EH (2002) Depression as bargaining - the case postpartum. Evol Hum Behav 23(5):323-336

Hay C, Fortson EN, Hollist DR, Altheimer I, Schaible LA (2006) The impact of community disadvantage on the relationship between the family and juvenile crime. J Res Crime Delinq 43(4):326-356

Hrdy SB (1999) Mother nature: maternal instincts and how they shape the human species. Ballantine Books, NY

Isabella RA (1993) Origins of attachment: maternal interactive behavior across the first year. Child Dev 64(2):605-621

Kobak R, Cassidy J, Lyons-Ruth K, Ziv Y (2006) Attachment, stress and psychopathology: a developmental pathways mode. In: Cicchetti D, Cohen E (eds) Handbook of developmental psychopathology, vol. III. University Press, Cambridge, pp 333-369

Mann J (1992) Nurture or negligence: maternal psychology and behavioral preference among preterm twins. In: Barkow J, Cosmides L, Tooby J (eds) The adapted mind: evolutionary psychology and the generation of culture. Oxford University Press, New York, pp 367-390

Muller-Nix C, Forcada-Guex M, Pierrehumbert B, Jaunin L, Borghini A, Ansermet F (2004) Prematurity, maternal stress and motherchild interactions. Early Hum Dev 79:145-158

NCHS (2008) National Vital Statitics-Annual Report 2008. Vermont Deparment Health, http://www.cdc.gov/nchs/nvss.htm

Nobile M, Giorda R, Marino C, Carlet O, Pastore V, Vanzin L, Bellina M, Molteni M, Battaglia M (2007) Socioeconomic status mediates the genetic contribution of the dopamine receptor D4 and serotonin transporter linked promoter region repeat polymorphisms to externalization in preadolescence. Dev Psychopathol 19(4):1147-1160

Noble KG, Norman MF, Farah MJ (2005) Neurocognitive correlates of socioeconomic status in kindergarten children. Dev Sci 8 (1):74-87

Noble KG, Farah MJ, McCandliss BD (2006) Socioeconomic background modulates cognition-achievement relationships in reading. Cogn Dev 21(3):349-368

Noble KG, McCandliss BD, Farah MJ (2007) Socioeconomic gradients predict individual differences in neurocognitive abilities. Dev Sci 10(4):464-480

Pederson DR, Moran G (1996) Expressions of the attachment relationship outside of the strange situation. Child Dev 67 (3):915-927

Plunkett JW, Meisels SJ, Stiefel GS, Pasick PL, Roloff DW (1986) Patterns of attachment among preterm infants of varying biological risk. J Am Acad Child Adolesc Psych 25(6):794-800

Poehlmann J, Fiese BH (2001) The interaction of maternal and infant vulnerabilities on developing attachment relationships. Dev Psychopathol 13(1):1-11

Rutter M (2006) Genes and behavior. Nature-nurture interplay explained. Blackwell, New York

Salmon C (2005) Parental investment and parent-offspring conflit. In: Buss DM (ed) The handbook of evolutionary psychology. Wiley, Hoboken, NJ, pp 506-527

Sameroff AJ (1975) Early influences on development — fact or fancy. Merrill-Palmer Q-J Dev Psychol 21(4):267-294

Sameroff A, Fiese B (2000) Transactional regulation: the developmental ecology of early intervention. In: Shonkoff J, Meisels S (eds) Handbook of early childhood intervention. Cambridge University Press, Cambridge, pp 135-159

Sameroff A, Seifer R, Zax M, Barocas R (1987a) Early indicators of developmental risk: Rochester longitudinal study. Schizophr Bull 13(3):383-394

Sameroff AJ, Seifer R, Barrocas B, Zax M, Greenspan S (1987b) IQ scores of 4-years-old children: social-environmental risk factors. Pediatrics 79(3):343-350

Schermann-Eizirik L, Hagekull B, Bohlin G, Persson K, Sedin G (1997) Interaction between mothers and infants born at risk during the first six months of corrected age. Acta Paediatrics 86(8):864-872

Simpson JA (1999) Attachment theory in modern evolutionary perspective. In: Cassidy J, Shaver P (eds) Handbook of attachment - theory, research and clinical applications. Guilford, New York

Sullivan PM, Knutson JF (1998) Maltreatment and behavioral characteristics of youth who are deaf or hard of hearing. Sex Disabil 16(4):295-319

Sullivan PM, Knutson JF (2000) Maltreatment and disabilities: a population-based epidemiological study. Child Abuse Neglect 24:1257-1273

Tifferet S, Manor O, Constantini S, Friedman O (2007) Parental investment in children with chronic disease: the effect of child's and mother's age. Evol Psychol 5(4):844-859 http://www. epjournal.net 
Tooby J, Cosmides L (1992) The psychological foundations of culture. In: Barkow J, Cosmides L, Tooby J (eds) The adapted mind: evolutionary psychology and the generation of culture. Oxford University Press, NY, pp 19-136

Trivers R (1972) Parental investment and sexual selection. In: Campbell B (ed) Sexual selection and the descent of man: 1871-1971. Aldine, Chicago, pp 136-179

Tronick EZ, Ricks M, Cohn JF (1982) Maternal and infant affective exchange: patterns of adapation. In: Field T, Fogel A (eds) Emotional and interaction: normal and high-risk infants. Erlbaum, Hillsdale, NJ, pp 83-100

Tronick EZ, Scanlon KB, Scanlon JW (1985) A comparative analysis of the validity of several approaches to the scoring of the behavior of the preterm infant. Infant Behav Dev 8 (4):395-411
Veenstra R, Lindenberg S, Oldehinkel AJ, De Winter AF, Verhulst FC, Ormel J (2005) Bullying and victimization in elementary schools: a comparison of bullies, victims, bully/victims, and uninvolved preadolescents. Dev Psychol 41(4):672-682

Werner E, Bierman JM, French FE, Simonian K, Connor A, Smith RS, Campbell M (1968) Reproductive and environmental casualties - a report on 10-year follow-up of children of kauai pregnancy study. Pediatrics 42(1):112-127

Wille DE (1991) Relation of preterm birth with quality of motherinfant attachment at one year. Infant Behav Dev 14:227-240

Zirpoli TJ (1986) Child abuse and children with handicaps. Remedial Spec Educ 7:39-48

Zirpoli TJ, Bell RQ (1987) Unresponsiveness in children with severe disabilities: potential effects on parent-child interactions. Except Child 34(1):31-40 